[Agr. Biol. Chem., Vol. 29, No. 2, p. 90 93, 1965]

\title{
Metabolism of Gallic Acid and Tea Catechin by Rabbıt
}

\author{
By Akira Watanabe* and Yasuyoshi Oshima \\ Department of Agricultural Chemistry, Faculty of Agriculture, \\ University of Kyushu, Fukuoka* \\ Received July 4, 1964
}

\begin{abstract}
Metabolism of gallic acid in the rabbit has been studied. Orally administered gallic acid was excreted mostly unchanged and partially as pyrogallol and 4-methoxy-3,5dihydroxybenzoic acid in the urine. Conjugates could hardly be found. Moreover, evidently by administration of gallic acid three phenolic acids in the urinary excretion were diminished compared with that of fed on the control diet. Effect of tea catechin was also studied.
\end{abstract}

There are many reports concerning metabolism of phenolic substances in the animal body. Namely, detoxication reactions such as conjugation, ${ }^{11}$ hydroxylation, ${ }^{2}$ methylation, ${ }^{3 \sim 8)}$ dehydroxylation, ${ }^{9 \sim 11)}$ and benzol nucleus decomposition ${ }^{12}$ have been known. In this reports, the metabolism of gallic acid and gallocatechin, and the effects on the excretion of other phenolic substances in the urine were studied after oral administration of these substances to rabbit. Gallic acid is ingested by man in the free form or as derivatives present in tea, and gallocatechin also constitutes about $5 \%$ of the tea catechins.

\footnotetext{
* Present address, Tokyo Research Laboratory (Tanabe Seiyaku Co., Ltd., Shimotoda, Toda-machi, Saitama.)

1) H. G. Bray et al., Biochem. J., 52, 416419 (1952).

2) H. G. Bray and W.V. Thorpe, "Method of Biochemical Analysis", Interscience Publishers. Inc., New York, 1954, Vol. I,P. 31 .

3) N. F. Maclagan and J.H. Wilkinson, Nature, 168, 251 (1951).

4) C. W. Murray, F. T. Jones and F. DeEds, J. Biol. Chem., 223, 251 (1956).

5) F. DeEds, A. N. Booth and F.T. Jones, ibid., 225, 615, (1957).

6) M.D. Armstrong and A. McMillan, Fed. Proc., 16, 146 (1957).

7) J. M. Price and L. W. Dodge, J. Biol. Chem., 223, 699 (1956).

8) A. N. Booth, F. T. Jones and F. DeEds, Fed., Proc., 15, 223 (1956).

9) H. Takahashi, M. Kaihara and J. M. Price, J. Biol. Chem. 223, 705 (1956).

10) H. Takahashi and J. M. Price, Fed. Proc., 16, 259 (1957).

11) M. Kaihara and J. M. Price, J. Biol. Chem., 238, 4082 (1963).

12) T. Tanaka et al., Published in The 8th Symposium of Enzyme Chemistry (Japan).
}

\section{MATERIALS}

Gallic acid and pyrogallol were commercial pro. ducts. The following compounds were synthesized for comparison with the metabolites in the urine. Homoprotocatechuic acid was prepared by demethylation of homoveratric acid ${ }^{13}$ by refluxing for three hours with three parts of pyridine hydrochloride. 14) $m$-Hydroxyphenylacetic acid was prepared from $m$ methoxyphenylacetic acid ${ }^{15}$ ) by demethylation with pyridine hydrochloride in the same way. 4-Methoxy3,5-dihydroxybenzoic acid,16) 3,4-dimethoxy-5-hydroxybenzoic acid, ${ }^{16}$ ) syringic acid, 17) 3-methoxy-4,5-dihydroxybenzoic acid,18) protocatechuic acid, ${ }^{19}$ ) $\mathrm{m}$ hydroxybenzoic acid,20) vanillic acid21 and homovanillic acid22) were synthesized by the methods described in the literature cited. Tea catechin was prepared by extraction of dried and powdered tea leaves with ethylacetate and pale brown product consisted of about $35 \%$ epigallocatechin and $d l$-gallocatechin and about 55\% gallocatechingallate and catechingallate.23)

\section{EXPERIMENTALS}

Two groups of 2 male rabbits of about $3 \mathrm{Kg}$ were

13) A. Pictet und M. Finkelstein, Ber, 42, 1984 (1909).

14) V. Prey, ibid., 75, 350 (1942).

15) R. Pschorr, Ann. 391, 43 (1912).

16) E. Fischer, M. Bergmann und W. Lipschitz, Ber,, 51 58,68 (1917)

17) W. H. Hunter and A.L. Arthur, J. Am. Chem. Soc. 48, 1610 (1926).

18) E. Fischer und K. Freudenberg, Ber., 46, 1123 (1913)

19) I. A Pearl, Org. Syn., 29, 85

20) H. Offermann, $A n n, 280,1$ (1894).

21) I. A. Pearl, Org. Syn. 30, 101.

22) A. Pictet und M. Finkelstein, Ber. 42, 1983 (1909).

23) Y. Oshima, T. Nakabayashi and S. Nishida, J. Agr. Chem. Soc. Japan, 26, 367 (1952). 
fed for a week with bean-curd leavings* only as the basal diet. To each animal of the group, $0.5 \mathrm{~g}$ of gallic acid or tea catechin per day per $\mathrm{Kg}$ of body weight was administered orally with the basal diet, respectively. The combined urine, collected in the receiving vessel, was kept acidic by addition of $10 \%$ hydrochloric acid to avoid oxidation of phenolic compounds. Over the period of 10 days were collected $6.8 \mathrm{~L}$ of urine from the gallic acid-fed, 7.11 from the tea catechin-fed and 5.01 from the basal diet-fed group.

\section{Extraction}

The collected urine, filtered and saturated with sodium chloride, was extracted three times with an equal volume of ethylacetate. The ethylacetate solution was dried with sodium sulfate and concentrated under vacuum in the nitrogen atmosphere. From the urine of the gallic acid- and the catechin-fed rabbits were obtained $14.5 \mathrm{~g}$ and $10.1 \mathrm{~g}$ of dark brown residues, respectively. In the same way, from the urine of control group was obtained $6.1 \mathrm{~g}$ of brown residue.

\section{Paperchromatography of the Extracts}

The components in the extracts were examined by two-dimension paperchromatography using solvent systems of chloroform-acetic acid-water $(2: 1: 1 \mathrm{~V} / \mathrm{V})$ and $20 \%$ aqueous solution of pottasium chloride. Each phenolic compound on the paperchromatogram was detected with the diazotized sulfanilic acidsodiumcarbonate aqueous solution ${ }^{24)}$ and compared with the authentic substances (Fig. 1).

The spots A, C and D were found only in the extracts of the urine of the gallic acid-fed rabbits and it was considered that $A, C$ and $D$ were pyrogallol, 4-methoxy-3,5-dihydroxybenzoic acid and gallic acid, respectively.

\section{Identification of $A, C$ and $D$}

\section{1) Separation of $A, C$ and $D$}

Two grams of the extracts from the urine of the gallic acid-fed rabbits was dissolved in $2 \mathrm{ml}$ of ethanol, absorbed in $2 \mathrm{~g}$ of cellulose powder (Toyoroshi $200 \sim 300$ mesh) and deposited on the top of a column of cellulose powder $(2.3 \mathrm{~cm} \times 45 \mathrm{~cm})$ and the ethanol of the top layer was removed by evacuating the column from the top. Elution was performed with 11 of

* Bean-curd leavings is the residue obtained by filtration of soluble proteins of the milk of ground and boiled soy beans through cloth in the process of bean-curd manufacture:

2A) H. G. Bray, W. V. Thorpe and K. White, Biochem. J., 46, 271 (1950).

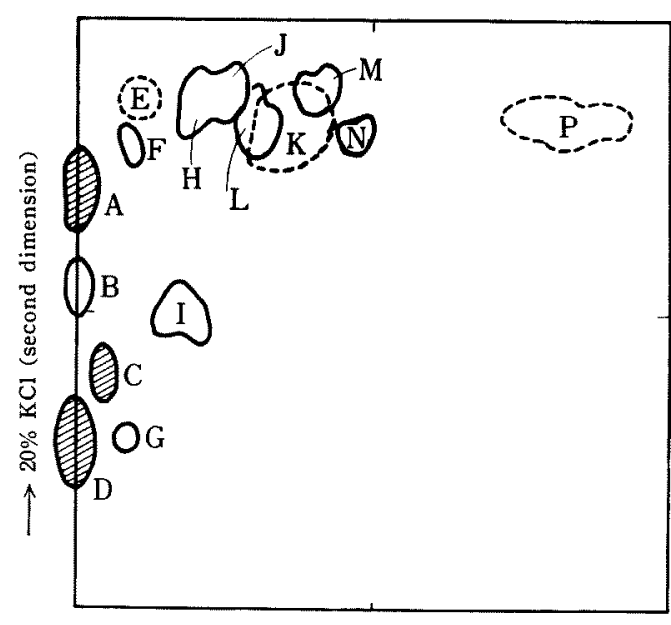

$\longrightarrow$ Chloroform-acetic acid-water (first dimension)

FIG. 1. Paperchromatogram of Ethylacetate Extracts of the Urine of Gallic Acid-fed Group and Control Group.

Colored with diazotized sulfanilic acid and $20 \% \mathrm{Na}_{2} \mathrm{CO}_{3}$.

- Spots found only for the gallic acid-fed group.

: Spots which were found for the control group and not found for the gallic acid-fed group.

A: Pyrogallol.

C: 4-Methoxy-3,5-dihydroxybenzoic acid.

D: Gallic acid

chloroform-acetic acid-water $(2: 1: 1 \mathrm{~V} / \mathrm{V})$ at a flow rate of $5 \mathrm{ml}$ per minute and each fraction contained $20 \mathrm{ml}$ of the effluent was collected. Substance C was found in the fractions No. $35 \sim 43$. The column was washed further with $200 \mathrm{ml}$ of the same solvent and dried completely under vacuum. Elution was restarted with $20 \%$ aqueous solution of pottasium chloride at a rate of $0.5 \mathrm{ml}$ per minute and each fraction contained $10 \mathrm{ml}$ of the effluent was collected. The substance $A$ was found in the fractions No. $15 \sim 18$ and the substance $D$ was found in the fractions No. $26 \sim 36$ by the paperchromatographic examination.

\section{2) Identification}

Substance A. Substance A was extracted from the combined corresponding fractions with ethylacetate. The ethylacetate solution was dried with sodium sulfate and evaporated under vacuum. The residue was recrystallized from water to give $50 \mathrm{mg}$ of crystals, m.p. $132^{\circ} \mathrm{C}$. Depression of the melting point was not observed when mixed with pyrogallol. Anal. Found: C, 57.12; H, 5.65. Calcd. for $\mathrm{C}_{6} \mathrm{H}_{6} \mathrm{O}_{3}: \mathrm{C}, 57.17 ; \mathrm{H}$, $5.80 \%$.

Substance C. Substance $\mathrm{C}$ was obtained from the 


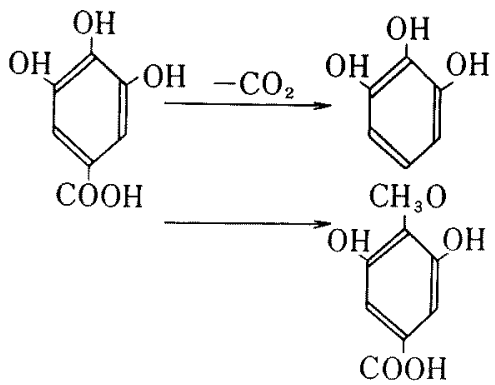

FIG. 2. Urinary Metabolites of Gallic Acid Fed to the Rabbit.

corresponding fractions in the same way. After recrystallization from water $35 \mathrm{mg}$ of crystals was obtained. m.p. $242^{\circ} \mathrm{C}$ (decomp). The infrared spectra of $\mathrm{C}$ and authentic sample 4-methoxy-3,5-dihydroxybenzoic acid showed no difference in absorption. Anal. Found: $\mathrm{C}, 52.08 ; \mathrm{H}, 4.32$. Calcd. for $\mathrm{C}_{8} \mathrm{H}_{8} \mathrm{O}_{5}$ : $\mathrm{C}$, $52.18 ; \mathrm{H}, 4.38 \%$.

Substance D. In the same way, substance $D$ was extracted from the corresponding fractions with ethylacetate. After evaporation of the solvent, the residue was recrystallized from water with aid of activated charcoal, and $45 \mathrm{mg}$ of white needle crystals were obtained. m.p. $250^{\circ} \mathrm{C}$ (sintering at $225^{\circ} \mathrm{C}$ ). Its $R_{F}$ value and color reaction were the same as those of gallic acid. Anal. Found: C, 49.35; H, 3.94. Calcd. for $\mathrm{C}_{7} \mathrm{H}_{6} \mathrm{O}_{5} ; \mathrm{C}, 49.42 ; \mathrm{H}, 3.55 \%$.

The ethylacetate-extracted urine was treated in $2 \mathrm{~N}$ $\mathrm{H}_{2} \mathrm{SO}_{4}$ at $100^{\circ} \mathrm{C}$ for one hour and extracted with ethylacetate. The components in the extract were examined in the same way and no conjugate of the metabolite of gallic acid was found.

In the case of the administration of tea catechins, the paperchromatogram of the extract of the urine was almost the same as in the case of the administration of gallic acid and the other spot with diazotized sulfanilic acid reagent, was not found.

Substance P, E and K (Fig. 1) were found only in the urine of basal diet-fed group and were presumed to be homovanillic acid, homoprotocatechuic acid and $m$-hydroxyphenylacetic acid respectively in view of the $R_{F}$ values and color reactions on the paperchromatogram.

\section{DISCUSSION}

It was found that gallic acid, fed to the rabbit orally in a large quantity, was excreted mostly unchanged in the urine, and some part of it was metabolized to pyrogallol and 4-methoxy-3, 5-dihydroxybenzoic acid. When gallocatechin was fed to the rabbit as the mixture of tea catechins, only the metabolites of gallic acid presumably originating from the gallates of the catechin mixture were found but the other blue or blue black spot that is characteristic of trihydroxyphenyl radical of gallocatechin with diazotized sulfanilic acid reagent was not found in the paperchromatogram. Therefore, it was considered that trihydroxyphenyl radical of gallocatechin underwent a rapid metabolic decomposition.

The remarkable difference of the urine components of the gallic acid-fed rabbit compared with that of control group was the disappearance of three phenollic acids. These acids are presumably homovanilic acid, homoprotocatechuic acid and $m$-hydroxyphenylacetic acid in view of the $R_{F}$ values and color reactions on the paperchromatogram. Previously Tompsett ${ }^{25)}$ reported that oral ingestion of tannic acid by man caused an increased excretion of both 3,4-dihydroxy and 3-methoxy4-hydroxy-benzoic acids. Though it has been known that the metabolism of phenolic com-

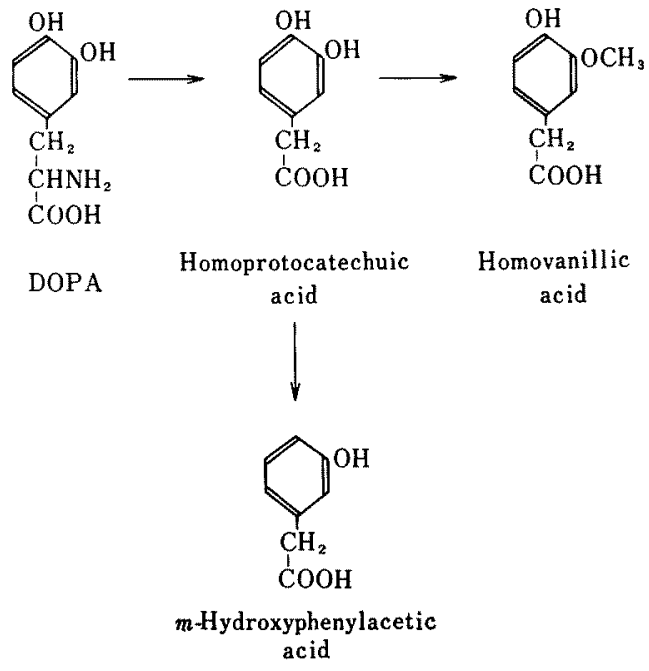

FIG. 3. Metabolic Transformation of DOPA.

25) S. L. Tompsett, J. Pharm. and Pharmacol., 11, 32 (1959). 


\section{Table 1. $R_{F}$ Values and Color Reactions of Phenolic Compounds}

Phenolic oxycarbonic acid

Gallic acid

3-Methoxy-4,5-dihydroxybenzoic acid

3,4-Dimethoxy-5-hydroxybenzoic acid Syringic acid

4-Methoxy-3,5-dihydroxybenzoic acid

Pyorogallol

$m$-Hydroxybenzoic acid

$m$-Hydroxyphenylacetic acid

Protocatechuic acid

Homoprotocatechuic acid

Vanillic acid

Homovanillic acid

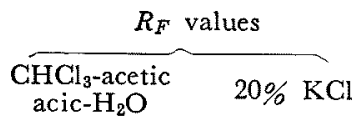

0

0.18

0.85

0.88

$0 \cdot 11$

0.05

0.41

0.47

0.03

0.07

0.88

0.78
0.33

0.32

0.50

0.33

0.51

0.61

0.56

0.84

0.41

0.80

0.43

0.85
Color with diazotized sulfanilic acid

Dark violet

Light violet

Orange-yellow

Red

Brown-yellow

Pale violet then dark brown

Yellow

Dark yellow

Violet

Violet

Orange

Light violet

pounds differs depending on the species of the animal generally, it is considered that the oral ingestion of gallic acid in a large quantity has some influence upon the metabolism of phenolic compounds such as DOPA, ${ }^{5)}$ and could have caused the disappearance of these

phenolic acids from the urine of the rabbit.

Acknowledgements. The authors express their sincere gratitude to Dr. M. Fujisawa and Dr. N. Sugimoto of Osaka Research Laboratory, Tanabe Seiyaku Co., Ltd. for their continuous interest and support. 